\title{
Polyionic polymers - heterogeneous media for metal nanoparticles as catalyst in Suzuki-Miyaura and Heck-Mizoroki reactions under flow conditions
}

\author{
Klaas Mennecke and Andreas Kirschning*
}

\author{
Full Research Paper \\ Address: \\ Institut für Organische Chemie and Zentrum für Biomolekulare \\ Wirkstoffe (BMWZ), Leibniz Universität Hannover, Schneiderberg 1B, \\ D-30167 Hannover, Germany \\ Email: \\ Andreas Kirschning* - andreas.kirschning@oci.uni-hannover.de \\ * Corresponding author \\ Keywords: \\ Heck-Mizoroki reaction; heterogeneous catalysis; ion exchange resin; \\ microreactor; monolith; palladium; Suzuki-Miyaura reaction
}

Open Access

Beilstein Journal of Organic Chemistry 2009, 5, No. 21 doi:10.3762/bjoc.5.21

Received: 28 March 2009

Accepted: 28 April 2009

Published: 08 May 2009

Guest Editor: A. Kirschning

(c) 2009 Mennecke and Kirschning; licensee Beilstein-Institut. License and terms: see end of document.

\begin{abstract}
The preparation of monolithic polyionic supports which serve as efficient heterogeneous supports for palladium(0) nanoparticles is described. These functionalized polymers were incorporated inside a flow reactor and employed in Suzuki-Miyaura and Heck cross couplings under continuous flow conditions.
\end{abstract}

\section{Introduction}

Functionalized solid supports like polymers loaded with homogeneous catalysts are well established in organic synthesis [1-4]. Simple purification of the products and easy recyclability of the catalysts are major advantages of heterogenization of transition metals. A major hurdle for industrial applications of heterogenized homogeneous metal catalyst is associated with keeping metal leaching down to a minimum. Immobilization can be regarded as one enabling technique in organic chemistry $[5,6]$ that in conjunction with continuous flow processes creates an ideal setup for an automated solution-phase synthesis. Furthermore, this combination of enabling techniques has great potential in the production of fine chemicals $[7,8]$.
In continuation of our efforts in developing immobilization concepts for reagents and catalysts including transition metals on solid phases inside monolithic flow reactors [9-18] we describe the preparation of palladium nanoparticles loaded on polyionic polymers and their use under continuous flow conditions in various C-C-cross-coupling reactions [19-22].

\section{Results and Discussion}

Preparation of the catalyst

Recently, we reported on the preparation of a monolithic polymeric material incorporated inside megaporous glass shaped Raschig-rings [11-18,23,24]. The polymeric phase was created 


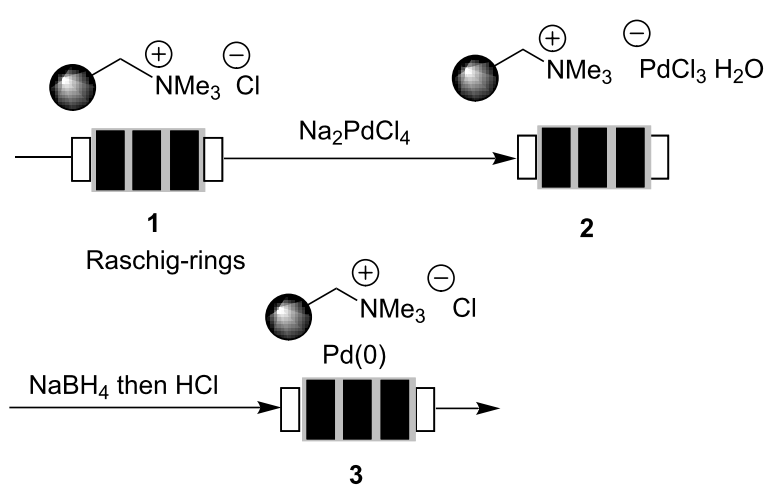

Scheme 1: Preparation of $\operatorname{Pd}(0)$ nanoparticles inside flow reactors.

by radical precipitation polymerization of styrene, vinylbenzyl chloride and divinylbenzene as monomers and consists of very small bead-like particles $(0.2-2 \mu \mathrm{m})$ which are connected through polymeric bridges. As a result an extended monolithic polymeric phase inside a glass monolith is created. Incorpora- tion of the resin inside a porous glass has the advantage that the resin can only swell inside the glass while the glass monolith provides a stable rod-like shape inside the microreactor. The Merrifield-type resin was aminated to yield polyionic support $\mathbf{1}$. This polymer serves as an anchor to leave the metal species (sodium tetrachloropalladate; $\mathrm{Na}_{2} \mathrm{PdCl}_{4}$ ) in close proximity to the ammonium group by means of ion exchange (Scheme 1). In the following, the active $\mathrm{Pd}$ particle is generated upon reduction with a solution of sodium borohydride. A particular benefit of the resulting solid support is the stabilization of the generated nanoparticles by the polymer-bound ammonium species [23-29]. These functionalized composite Raschig-rings are incorporated inside the flow microreactor which has a dead volume of about 1-2 mL (Figure 1) [30]. We could show that the palladium clusters are composed of palladium nanoparticles. Particle sizes highly depend on the monomer composition of the polyionic support [4-vinylbenzyl chloride (VBC), divinylbenzene (DVB), styrene]. Depending on the particle diameter a large impact on their catalytic performance (batch vs. flow; conventional vs. microwave heating) was noted [24]. In this context these materials have clear advantages over $\operatorname{Pd}(0)$ on
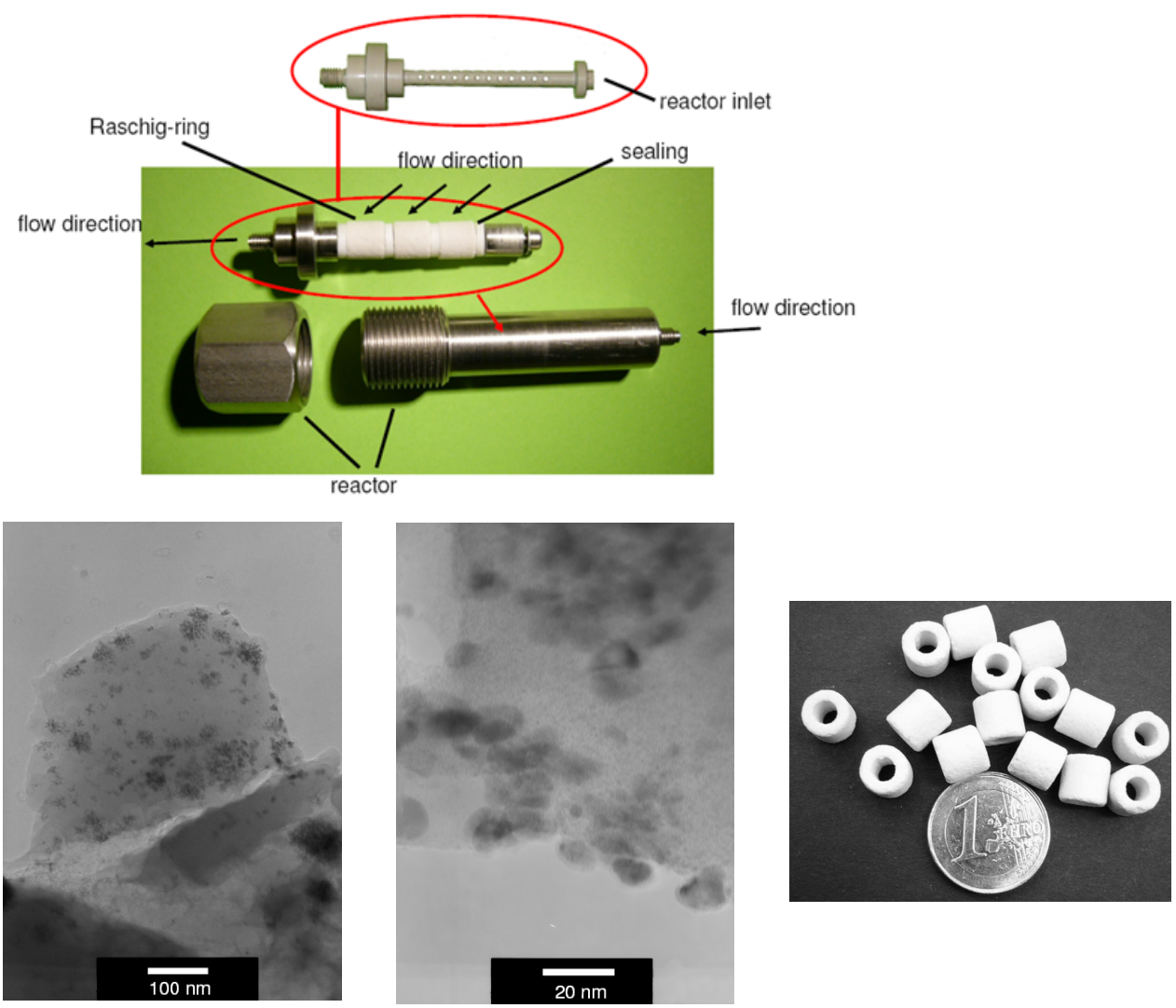

Figure 1: Top: Reactor (1-2 $\mathrm{mL}$ dead volume) with functionalized Raschig-rings; bottom: TEM-micrographs of $\mathrm{Pd}(0)$ nanoparticles on optimized polyionic gel (left and central) and Raschig-rings (right). 
charcoal because the latter cannot be further optimized with respect to the mode of application [31-33]. In the present study, our highly optimized composite material was chosen $(5.3 \%$ DVB crosslinker and a 1:1 mixture of VBC/styrene) doped with nanoparticles $(7-10 \mathrm{~nm}$ in size and a palladium content of 0.03 weight $\% \mathrm{Pd}$ on polyionic polymer).

\section{Suzuki-Miyaura cross coupling reactions}

In our earlier work we showed that these materials are well suited for transfer hydrogenations under flow conditions [23, 24]. Recently, the Suzuki-Miyaura reaction and other palladium catalyzed reactions have emerged as industrially very desirable processes and miniflow fixed bed reactors loaded with $\operatorname{Pd}(0)$ nanoparticles should be well suited to perform these C-C coupling reactions [34]. A particular challenge for utilizing the Suzuki-Miyaura reaction in flow devices is the quest for truly homogeneous reaction conditions in order to prevent clogging of the irregular microchannels. We chose the coupling of 4'-bromoacetophenone and phenylboronic acid as model reaction for optimizing the process and found that $85 \%$ conversion could be achieved within $10 \mathrm{~min}$ at $95^{\circ} \mathrm{C}$ in DMF/water $10 / 1$ with $2.5 \mathrm{~mol} \%$ of catalyst 3 using $\mathrm{CsF}$ as base. The reaction was performed in a cyclic mode with a flow rate of $2 \mathrm{~mL} / \mathrm{min}$. Single pass experiments with flow rates between 0.1 and $1 \mathrm{~mL} /$ min did not result in improved results, so that we commonly operated the system as a closed loop reactor in the following.

Under these optimized conditions several examples of successful cross coupling reactions were achieved that are listed in Table 1. We included combinations of electron rich and electron deficient aryl bromides with functionalized boronic acids and yields of coupling products were commonly good to excellent. Aryl chlorides did not react with catalyst 3 under flow conditions.

To fully explore the potential of polyionic gel 3 its reusability was investigated next. The Suzuki reaction of 4-bromotoluene (6) with phenylboronic acid (10) served as model reaction. After each reaction the continuous flow reactor was regenerated by pumping a solution of DMF/water $(10: 1,40 \mathrm{~mL})$ through the reactor before the next run was initiated (Figure 2). The palladium particles inside the flow reactor showed excellent stability without loss of activity after the tenth run. Palladium leaching was determined to be about $0.7 \mathrm{ppm}$ for each run. This very low value for leaching corresponds to the leaching determined for transfer hydrogenations with this catalytic flow system using cyclohexene as hydrogen source and solvent $[23,24]$.

Table 1: Suzuki-Miyaura reactions catalyzed by Pd nanoparticles 3 inside flow reactors.

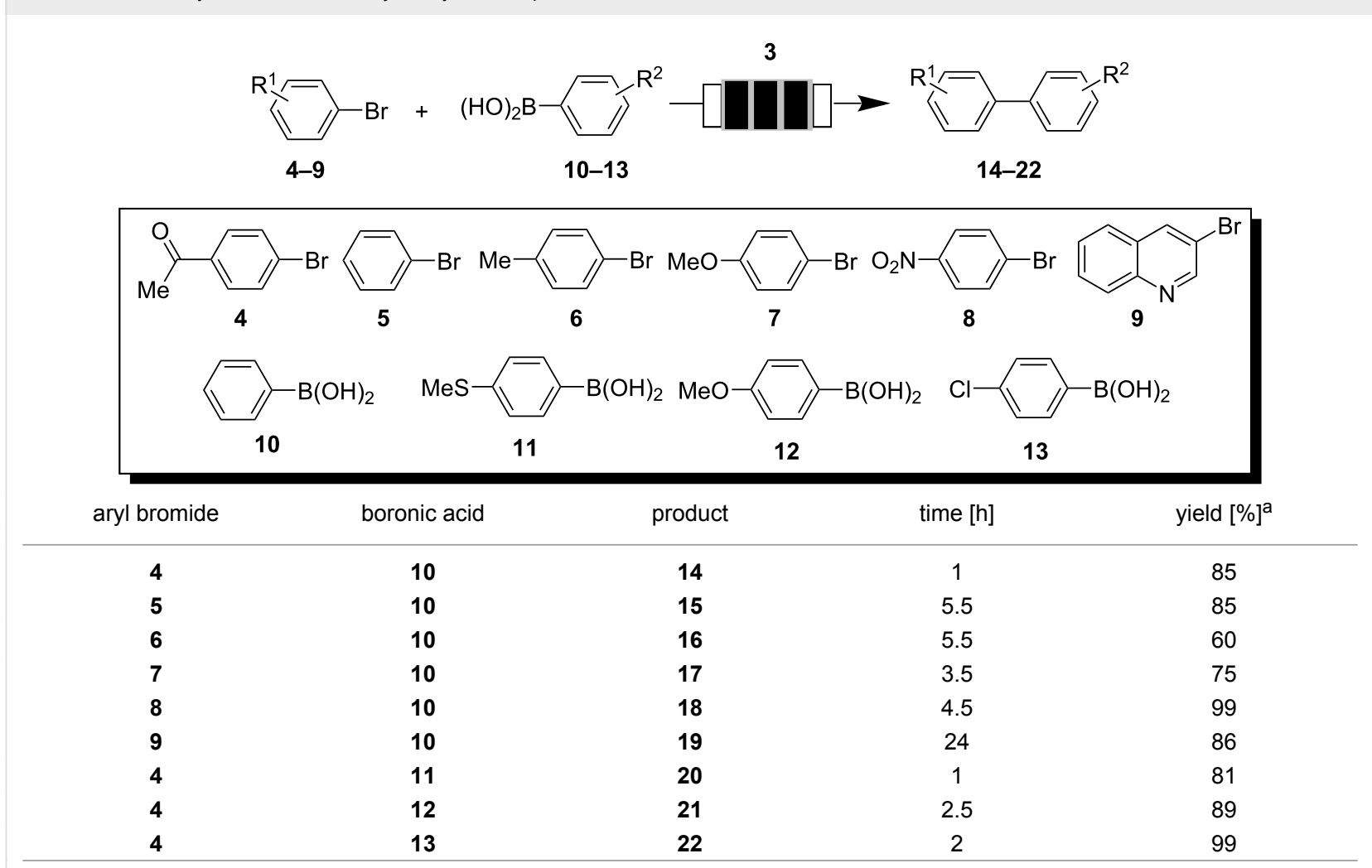

asolated yield of pure product. 


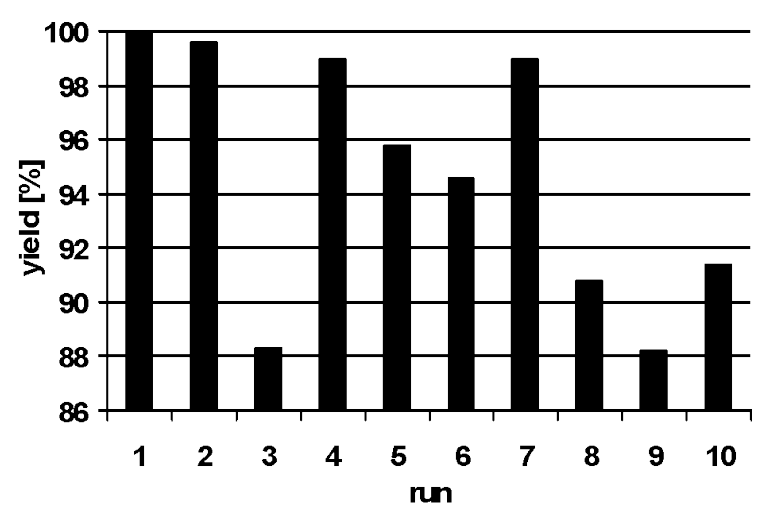

Figure 2: Repeated Suzuki reaction of 4-bromotoluene $(6)$ with phenylboronic acid (10) under flow conditions. Deviations may result from work up as only isolated yields are presented.

\section{Heck-Mizoroki reactions}

One other very important cross coupling reaction that bears industrial relevance is the Heck-Mizoroki reaction. We were able to perform $\mathrm{C}-\mathrm{C}$ coupling reaction under flow conditions with aryl iodides $\mathbf{2 3 - 2 8}$ using catalyst $\mathbf{3}$ (Table 2). Optimization of the conditions for our monolithic flow reactor was conducted with 4 '-iodoacetophenone (23) and styrene (29) as coupling partners. With $n$-butylamine as base and $2.5 \mathrm{~mol} \%$ catalyst 3 in DMF at $120^{\circ} \mathrm{C}$ and a flow rate of $2 \mathrm{~mL} / \mathrm{min}$ it was possible to achieve full conversion with complete $E$-selectivity within $30 \mathrm{~min}$. Formation of by-products resulting from homocoupling was not observed. When 4 '-iodoacetophenone (23) was exchanged with $4^{\prime}$-bromoacetophenone coupling with styrene yielded Heck-product $\mathbf{3 0}$ in only $35 \%$.

In order to generalize the reaction protocol different aryl iodides were coupled with styrene. In all cases, the C-C coupling products were formed within 0.5 to $24 \mathrm{~h}$ in very good yield with excellent stereocontrol (see Table 2). Palladium leaching was determined to be $0.04 \%$ for each run based on the catalyst used initially, which is an exceptionally low value in view of the fact that DMF a well coordinating solvent is employed [35].

Even commercially available and widely employed catalysts that are based on encapsulated Pd particles such as PdEnCat [35] show a similarly low degree of leaching in DMF to our Pd nanoparticles [36]. With reference to the fundamental work by Reetz and de Vries the ionic environment on the polymer phase that is located in very close vicinity to the palladium nanoparticles has very likely to be made responsible for the stabilization of the nanoparticles which results in low degree of leaching [25-29].

It has to be noted that like many other heterogenized Pd sources $[15,16,36-41]$ these polyionic gels very likely also serve as
Table 2: Heck-Mizoroki reactions catalyzed by Pd nanoparticles 3 inside flow reactors.

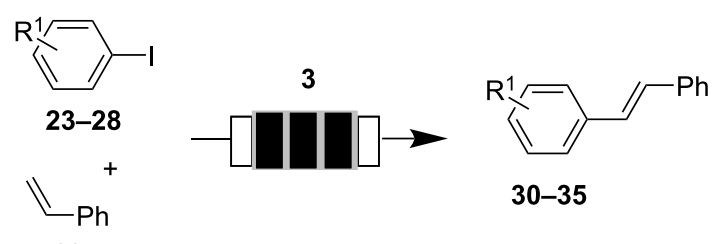

29

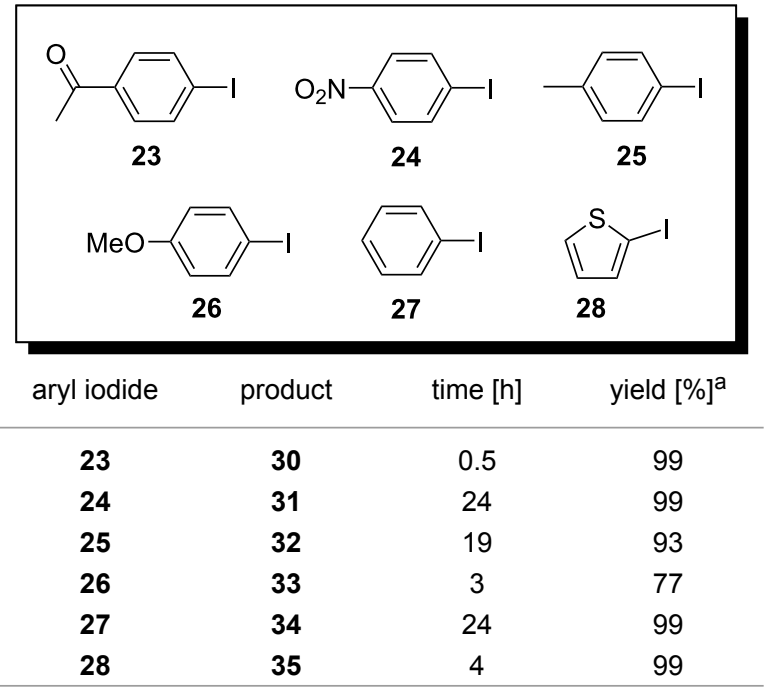

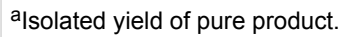

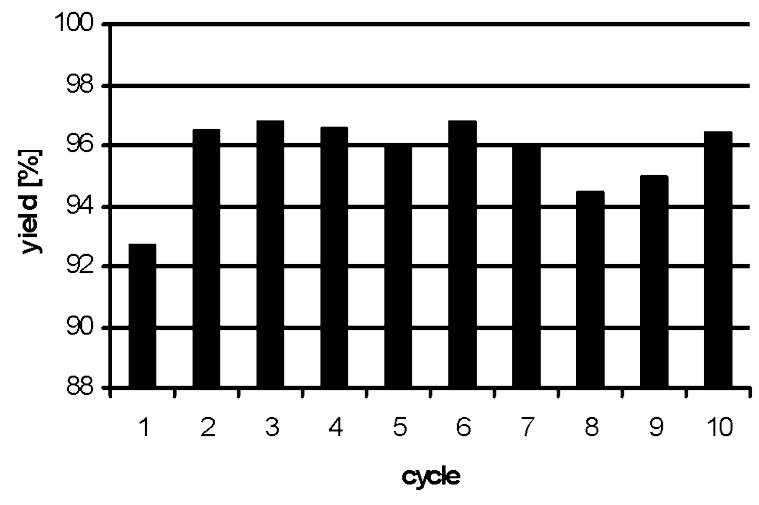

Figure 3: Repeated Heck-Mizoroki reaction of 4'-iodoacetophenone (23) with styrene (29) under flow conditions.

reservoirs for Pd nanoclusters that are released into solution at very low concentrations. With respect to transfer hydrogenations using precatalyst 3 we recently conducted a thorough study on the principal question whether $\mathbf{3}$ serves as a Pd reservoir [23]. As was first demonstrated by Reetz [25-28] and de Vries [29] these clusters exert pronounced catalytic activity in solution at very low concentrations. This view is further supported by the fact that the catalytic species operating in the 
present case is able to promote Suzuki-Miyaura cross coupling reactions with aryl bromides while aryl chlorides are not good substrates under these standard conditions. This observation has been noted in many examples of heterogenized palladium salts or complexes [34]. Likewise, these species are commonly not reactive enough to promote the Heck-Mizoroki reaction with aryl bromides. It should be noted that under supercritical or high pressure/high temperature conditions aryl chlorides (for Suzuki-Miyaura reactions) or aryl bromides (for Heck-Mizoroki reactions) may very well serve as substrates for this kind of palladium species.

\section{Conclusion}

In summary, we demonstrated that polyionic gel $\mathbf{3}$ is a well suited ion exchange resin for the generation of metal nanoparticles. The ionic nature of the resin has a positive impact on the stabilization of the Pd species which results in extended use for Suzuki-Miyaura cross coupling reactions as well as Heck reactions without substantial reduction of activity even when solvents such as DMF are employed and therefore leads to a minimum degree of leaching. The ease of preparation and the properties of polyionic catalyst $\mathbf{3}$ make it an attractive catalytic monolith for industrially relevant continuous flow processes particularly when employed in combination with a scavenger column for removing traces of soluble Pd species.

\section{Supporting Information}

\author{
Supporting Information File 1 \\ Experimental \\ [http://www.beilstein-journals.org/bjoc/content/ \\ supplementary/1860-5397-5-21-S1.doc]
}

\section{Acknowledgments}

This work was supported by the Fonds der Chemischen Industrie and the Deutsche Forschungsgemeinschaft (grant 397/6-1). We are grateful to U. Kunz (Institute of Chemical Engineering, Technical University of Clausthal, Germany) for supporting us in all issues concerning flow reactor design.

\section{Note added in proof}

In a detailed study McQuade and coworker demonstrated that PdEnCat 30 also behaves as heterogeneous sources for soluble, catalytically active species during the course of Heck and Suzuki couplings. They note a solution-phase contribution for catalysis and determined leaching up to $46 \%$ in DMF as solvent which is significantly higher compared to our polyionic gels: Broadwater, S. J.; McQuade, D. T. J. Org. Chem. 2006, 71, 2131-2134.

\section{References}

1. Kirschning, A., Ed. Immobilized Catalysts: Solid Phases, Immobilization and Applications; Topics in Current Chemistry, Vol. 242; Springer: Berlin, 2004. doi:10.1007/b94543

2. Frenzel, T.; Solodenko, W.; Kirschning, A. Solid-Phase Bound Catalysts: Properties and Applications. In Polymeric Materials in Organic Synthesis and Catalysis; Buchmeiser, M. R., Ed.; Wiley-VCH: Weinheim, 2003; pp 201-240. doi:10.1002/3527601856.ch4

3. Li, C. Catal. Rev. - Sci. Eng. 2004, 46, 419-492. doi:10.1081/CR-200036734

4. Xia, Q.-H.; Ge, H.-Q.; Ye, C.-P.; Liu, Z.-M.; Su, K.-X. Chem. Rev. 2005, 105, 1603-1662. doi:10.1021/cr0406458

5. Kirschning, A.; Solodenko, W.; Mennecke, K. Chem.-Eur. J. 2006, 12, 5972-5990. doi:10.1002/chem.200600236

6. Jas, G.; Kirschning, A. Chem.-Eur. J. 2003, 9, 5708-5723. doi:10.1002/chem.200305212

7. Blaser, H.-U. Chem. Commun. 2003, 293-296. doi:10.1039/b209968n

8. Blaser, H. U.; Schmidt, E., Eds. Asymmetric Catalysis on Industrial Scale - Challenges, Approaches and Solutions; Wiley-VCH, 2004.

9. Kirschning, A.; Altwicker, C.; Dräger, G.; Harders, J.; Hoffmann, N.; Hoffmann, U.; Schönfeld, H.; Solodenko, W.; Kunz, U.

Angew. Chem., Int. Ed. 2001, 40, 3995-3998. doi:10.1002/1521-3773(20011105)40:21<3995::AID-ANIE3995>3.0.CO ;2-V

Angew. Chem. 2001, 113, 4118-4120.

doi:10.1002/1521-3757(20011105)113:21<4118::AID-ANGE4118>3.0. $\mathrm{CO} ; 2-\mathrm{H}$.

10. Solodenko, W.; Kunz, U.; Jas, G.; Kirschning, A. Bioorg. Med. Chem. Lett. 2002, 12, 1833-1835. doi:10.1016/S0960-894X(02)00265-2

11. Kunz, U.; Schönfeld, H.; Kirschning, A.; Solodenko, W. J. Chromatogr., A 2003, 1006, 241-249. doi:10.1016/S0021-9673(03)00556-9

12. Kunz, U.; Kirschning, A.; Wen, H.-L.; Solodenko, W.; Cecilia, R.; Kappe, C. O.; Turek, T. Catal. Today 2005, 105, 318-324. doi:10.1016/j.cattod.2005.06.046

13. Dräger, G.; Kiss, C.; Kunz, U.; Kirschning, A. Org. Biomol. Chem. 2007, 5, 3657-3664. doi:10.1039/b712804e 14. Solodenko, W.; Jas, G.; Kunz, U.; Kirschning, A. Synthesis 2007, 583-589. doi:10.1055/s-2007-965877

15. Michrowska, A.; Mennecke, K.; Kunz, U.; Kirschning, A.; Grela, K. J. Am. Chem. Soc. 2006, 128, 13261-13267. doi:10.1021/ja063561k

16. Mennecke, K.; Solodenko, W.; Kirschning, A. Synthesis 2008, 1589-1599. doi:10.1055/s-2008-1072579

17. Mennecke, K.; Kirschning, A. Synthesis 2008, 3267-3272. doi:10.1055/s-2008-1067274

18. Ceylan, S.; Friese, C.; Lammel, C.; Mazac, K.; Kirschning, A. Angew. Chem. 2008, 120, 9083-9086. doi:10.1002/ange.200801474 Angew. Chem., Int. Ed. 2008, 47, 8950-8953. doi:10.1002/anie.200801474.

19. Nikbin, N.; Ladlow, M.; Ley, S. V. Org. Process Res. Dev. 2007, 11, 458-462. doi:10.1021/op7000436 20. Lee, C. K. Y.; Holmes, A. B.; Ley, S. V.; McConvey, I. F.; Al-Duri, B.; Leeke, G. A.; Santos, R. C. D.; Seville, J. P. K. Chem. Commun. 2005, 2175-2177. doi:10.1039/b418669a

21. Fukuyama, T.; Shinmen, M.; Nishitani, S.; Sato, M.; Ryu, I. Org. Lett. 2002, 4, 1691-1694. doi:10.1021/ol0257732

22. Fukuyama, T.; Rahman, M. T.; Sato, M.; Ryu, I. Synlett 2008, 151-163. doi:10.1055/s-2007-1000884 And references cited therein. 
23. Solodenko, W.; Wen, H.; Leue, S.; Stuhlmann, F.;

Sourkouni-Argirusi, G.; Jas, G.; Schönfeld, H.; Kunz, U.; Kirschning, A. Eur. J. Org. Chem. 2004, 3601-3610. doi:10.1002/ejoc.200400194

24. Mennecke, K.; Cecilia, R.; Glasnov, T. N.; Gruhl, S.; Vogt, C.; Feldhoff, A.; Larrubia Vargas, M. A.; Kappe, C. O.; Kunz, U.; Kirschning, A. Adv. Synth. Catal. 2008, 350, 717-730. doi:10.1002/adsc.200700510

25. Reetz, M. T.; Helbig, W. J. Am. Chem. Soc. 1994, 116, 7401-7402. doi:10.1021/ja00095a051

26. Reetz, M. T.; Quaiser, S. A. Angew. Chem., Int. Ed. Engl. 1995, 34, 2240-2241. doi:10.1002/anie.199522401 Angew. Chem. 1995, 107, 2461-2463.

27. Reetz, M. T.; Breinbauer, R.; Wanninger, K. Tetrahedron Lett. 1996, 37, 4499-4502. doi:10.1016/0040-4039(96)00924-0

28. Reetz, M. T.; Lohmer, G. Chem. Commun. 1996, 1921-1922. doi:10.1039/cc9960001921

29. de Vries, A. H. M.; Mulders, J. M. C. A.; Mommers, J. H. M.; Henderickx, H. J. W.; de Vries, J. G. Org. Lett. 2003, 5, 3285-3288. doi:10.1021/ol035184b

30. Kunz, U.; Schönfeld, H.; Solodenko, W.; Jas, G.; Kirschning, A. Ind. Eng. Chem. Res. 2005, 44, 8458-8467. doi:10.1021/ie048891x

31. Niederer, J. P. M.; Arnold, A. B. J.; Hölderich, W. F.; Spliethoff, B.; Tesche, B.; Reetz, M.; Bönnemann, H. Top. Catal. 2002, 18, 265-269. doi:10.1023/A:1013898807856

32. Toshima, N.; Shiraishi, Y.; Teranishi, T.; Miyake, M.; Tominaga, T.; Watanabe, H.; Brijoux, W.; Bönnemann, H.; Schmid, G. Appl. Organomet. Chem. 2001, 15, 178-196. doi:10.1002/aoc.146

33. Reetz, M. T.; Schulenburg, H.; Lopez, M.; Spliethoff, B.; Tesche, B. Chimia 2004, 58, 896-899.

34. Farina, V. Adv. Synth. Catal. 2004, 346, 1553-1582. doi:10.1002/adsc. 200404178 Review.

35. Baxendale, I. R.; Griffiths-Jones, C. M.; Ley, S. V.; Tranmer, G. K. Chem.-Eur. J. 2006, 12, 4407-4416. doi:10.1002/chem.200501400

36 . See reference [35] and references cited therein.

37. Richardson, J. M.; Jones, C. W. J. Catal. 2007, 251, 80-93. doi:10.1016/j.jcat.2007.07.005

38. Weck, M.; Jones, C. W. Inorg. Chem. 2007, 46, 1865-1875. doi:10.1021/ic061898h

39. Astruc, D. Inorg. Chem. 2007, 46, 1884-1894. doi:10.1021/ic062183h

40. Köhler, K.; Kleist, W.; Pröckl, S. S. Inorg. Chem. 2007, 46, 1876-1883. doi:10.1021/ic061907m

41. Thathagar, M. B.; ten Elshof, J. E.; Rothenberg, G. Angew. Chem., Int. Ed. 2006, 45, 2886-2890. doi:10.1002/anie.200504321

\section{License and Terms}

This is an Open Access article under the terms of the Creative Commons Attribution License

(http://creativecommons.org/licenses/by/2.0), which permits unrestricted use, distribution, and reproduction in any medium, provided the original work is properly cited.

The license is subject to the Beilstein Journal of Organic Chemistry terms and conditions:

(http://www.beilstein-journals.org/bjoc)

The definitive version of this article is the electronic one which can be found at: doi:10.3762/bjoc.5.21 